\title{
Role of slaughter facilities management in zoonoses and safety of meat produced for human consumption in Nigeria: a review
}

\author{
Salisu Ibrahim ${ }^{*} \mathbb{D}$, Bilkisu Yunusa Kaltungo ${ }^{2}$, Hajara Buhari Uwale ${ }^{3}$, Alhassan Yunusa Baba ${ }^{4}$, \\ Shehu Na-Allah Saidu', Farouk Umar Mohammed² and Hashimu Mohammed Dahiru ${ }^{5}$
}

\begin{abstract}
Background: This study attempts to review the role of slaughter facilities management of all zoonotic diseases encountered at the abattoirs as well as the safety of meat produced for public consumption in abattoirs in Nigeria. Good hygienic practices were totally absent in the abattoirs. There were dilapidated slaughtering and processing facilities, inadequate clean water supplies, no refrigerators and lack of facilities for the collection and storage of waste. Zoonotic agents demonstrated in slaughtered animals in Nigeria include Mycobacterium tuberculosis, Mycobacterium bovis, Leptospira species, Campylobacter species, Yersinia species, Clostridia species., Brucella abortus, Brucella melitensis, Brucella suis, and Salmonella spp. Other disease-causing infectious agents encountered at the abattoirs include Echerichia coli O157, Salmonella and Campylobacter species. The meat transportation is done by motor bike, wheel barrows and open vehicles and this become sources of physical contamination.

Main Body: Animals were not being examined regularly before or after slaughter, offals were washed with drainage water, effluent from drainage systems and that meat and organs cleaned from such drainages were sold to the public, leading to unsafe meat being released for public consumption. Meat and carcasses were conveyed out of the abattoir using unhygienic means of transport. Butchers and many abattoir workers were observed not using protective clothing during operations. Waste disposal was indiscriminate not regularly carried out which was hazardous to the environment, while the authorities concerned were not making any effort to improve the situation. Diseases such as Contagious Bovine Pleuropneumonia, Fasciolosis, Tuberculosis and Helminthoses were most frequently encountered some of the diseases were of public health and economic importance.

Conclusion: Meat Inspection and hygiene Act shall be enacted and signed into law. Provision of waste disposal system such as incinerators are recommended. The drainage system should be upgraded and modernized. Use of abattoir waste as a manure and the slurry as fertilizer is also recommended. In Nigeria none of the abattoirs met the minimum hygienic standard of operation as recommended by the Codex Alimentarius and they could not have supported the production of safe meat and meat products for human consumption.
\end{abstract}

Keywords: Facilities, Meat, Management, Zoonoses, Consumption, Public

\footnotetext{
*Correspondence: sihadejia@gmail.com

1 Department of Veterinary Medicine, Ahmadu Bello University, Zaria, Nigeria

Full list of author information is available at the end of the article
}

\section{Background}

Studies in Nigeria established that poor waste management is responsible for the environmental and health hazards associated with abattoirs (Lawan et al. 2010). On entering most abattoirs in Nigeria, one immediately sees the glaring evidence of a poor sanitation and hazardous 
environment. This includes dilapidated slaughtering and processing facilities, inadequate clean water supplies, no refrigerators and lack of facilities for the collection and storage of waste (Nwanta et al. 2008). Proper sewage or waste disposal systems are also lacking. Wastes are disposed directly into streams and rivers are very common in Nigeria (Nwanta et al. 2008). There is no disposal management or treatment system. And, the meat is also washed in the same water. The animal waste such as blood, bones, intestinal content, tissues, hides and skin are scattered in huge piles in and around the abattoirs (Lawan et al. 2010). This attracts flies and a stench that affects adjoining residences. All these hazards are as a result of untrained abattoir personals as well as butchers that are ignorant of sanitary principles and poverty. The waste is also responsible for environmental change, stigmatisation of residences and depreciation in the value of adjacent properties (Nwanta et al. 2008). The animal waste and waste water contribute to adverse health outcome. Zoonotic agents that have also been demonstrated in slaughtered animals in Nigeria include Mycobacterium tuberculosis, Mycobacterium bovis, Leptospira spp, Campylobacter sp, Yersinia sp, Clostridia spp, Listeria, among others (Adesemoye et al. 2006; Opara et al. 2006). Other disease-causing infectious agents encountered at the abattoirs include Echerichia coli (E. coli) O157, Salmonella and Campylobacter (Tekki et al. 2012). Others include Brucella abortus, Brucella melitensis, Brucella suis, and Salmonella spp (Cadmus et al. 2010; Kaltungo 2018a, b). The meat transportation is done by motor bike, wheel barrows and open vehicles which have multipurpose use such as carrying cement, timbers and any item to be carried from markets and this become sources of physical contamination (Nwanta et al. 2008).

\section{Main text}

An abattoir is a facility or premise approved and registered by the controlling authority for hygienic slaughtering and inspection of animals, processing and effective preservation and storage of meat products for human consumption (Merck Veterinary Manual (MVM) 1998; Fitzgerald 2010). Abattoirs may be classified into categories depending on available facilities within such slaughter facilities. Thus, there can be slaughter slabs which are commonly located in rural and semi-urban areas, slaughterhouses that can be found in Local Government Headquarters and abattoirs that are found in States and Federal Capital Territory capitals (Blood and Studdert 1990; Guidelines for the Slaughter of Animals 2020). This structuring of slaughter facilities is based on the Local Government Reform Act of 1976 by the Federal Government of Nigeria. (Dasuki commission 1976). The animals most commonly slaughtered for food are cattle (beef), sheep, goats and pigs (pork), and poultry (Guidelines for the Slaughter of Animals; MVM 1998; Yakubu 2016). Horses are also slaughtered for meat mostly in Europe and parts of Nigeria (Shehu et al. 2019).

The essence of having slaughter facilities in countries is to ensure the of release wholesome meat and meat products to communities as to ensure efficient health of the communities as to provide enough manpower for the teaming activities in such communities. The Federal Government has been working hard to roll in an Act that will enforce the supply of hygienic meat and meat products in Nigeria. To date this Act is still in the pipeline. However, The Federal Government has produced a guideline for the establishment of standard abattoirs in line with the Food and Agriculture Organization (FAO) under the banner of technical guidance: Principles of risk-based meat inspection and their application (FAO 2019).

A number of workers have dwelled into the study of the situations in Nigerian slaughter facilities. Such workers include Nwanta et al. (2008), Lawan et al. (2010), Tekki et al. (2012) and Muhammad (2017) among others.

This paper looked at the status of the management of these slaughter facilities in the various states of the federation and in the end provides suggestions as to how best these slaughter facilities should be managed with a view to ensuring good human health.

\section{Types of slaughter facilities in Nigeria}

There seems to be adequate provision of slaughter facilities in all the states of Nigeria with the number varying as to what type of facility is available vis-a-vis its sanitary measures and man power to manage it. This statement is based on the legal provisions by the Dasuki Commission that rolled out the Local Government Reforms in 1986 as well as the template abattoir model developed by the Federal Department of Livestock and Pest Control Services under the Ministry of Agriculture and Rural Development in the early 1990s. In the provision by the Dasuki Commission, LGCs are empowered to have the right to open and manage slaughter slabs and slaughter houses. Furthermore, the Fourth Schedule of the 1999 Constitution of Nigeria, subsection 1(e) states, amongst others, that the main functions of the Local Government Councils in the area of agriculture will be the "establishment, maintenance and regulation of slaughterhouses, markets, motor parks and public conveniences" (Dasuki commission 1976).

Nwanta et al. (2008) reported that there are over 30 abattoirs, 132 slaughterhouses and 1077 slaughter slabs in Nigeria with as many or even more than $14,127,868$ animals annually. They further reported that the establishment and management of abattoirs and wastes in Nigeria have always been regarded as social services by all the 
three tiers of government. However, as a deviance from that many abattoirs has been turned into living quarters as Nwanta et al. (2008) reported that in Oko-oba abattoir in Lagos, Nigeria, lairages where cattle are supposed to be kept overnight before slaughter have been turned into living quarters. They also reported that conveniences provided in the abattoirs for abattoir workers were dysfunctional and hoodlums found them handy for their illegal activities. The management of the Oko-oba abattoir had also allowed abattoir workers to dispose the waste from the abattoir into the nearby gutters and canal that were near to the abattoir. Such reports have been made by Lawan et al. (2010) in their study of abattoir management in North Western States of Nigeria. These studies indicated that the electrically operated rails, the floors, windows and doors had all given way with the results that these facilities never looked as slaughter facilities. The state of affairs as reported here may be due to lack of enforcement of the existing laws and regulations as observed by Tekki et al. (2012) as they found the Local Government authorities were more interested in revenue generation than the real reasons for opening slaughter facilities in their areas.

On his own, Fasanmi (2002) opined that abattoir should be publicly administered with a budget independent of the national or municipal administration as the provision of abattoir is a social service. At Zoo town in TransAmadi, Port Harcourt, Nigeria, the abattoir wastes were reported to be channeled directly into river Okpoka, a tributary of the Bonny River (Odeyemi 1991).

Many of the abattoirs in Nigeria have been reported to operate below the international standards as to provide hanging rails, potable water, steam for washing abattoir floors after daily operations, cold rooms and automated facilities for the removal of carcasses and wastes among others. For example, in a study to determine the level of management at some abattoirs in four North Western States of Nigeria Lawan et al. (2010) reported that there was no carcass hanging facilities in most of the abattoirs under their study. They also reported that offals were washed with drainage water, effluent from drainage systems and that meat and organs cleaned from such drainages were sold to the public. Similarly, Ibrahim (2016) reported butchers and many abattoir workers not using protective clothing during operations. All these can result in the transmission and even spread of tuberculosis and other diseases, should the organisms be around.

The fact that there is no sustainability and maintenance culture in the development of activities in most Nigerian public and even private sectors mean that abattoirs will not be run in the utmost states. The Public water supply is erratic while the electricity generation has gone far below $30 \%$ as, in some areas, there might be no electricity supply for months. In such a situation, one would not expect to have good working abattoir facilities even if they are functional. The construction of the abattoir buildings are also substandard as one could see cracks here and there in many of the abattoirs (Lawan et al. 2010). In many instances there may be no sewage or waste disposal systems, and that adequate clean water supplies and refrigeration may be absent. The poor electricity supply along with poor maintenance culture in the body system of Government activities have made all the processes in many if not all the slaughter facilities in Nigeria to be left to be desired (Cadmus et al. 2004; Nwanta et al. 2008; Lawan et al. 2010).

\section{Animals for slaughter for meat consumption}

Animals most commonly slaughtered for human consumption in Nigeria include cattle, small ruminants, and pigs with camels being slaughtered once a while in many of the North Western and North Eastern states of the country (Nwanta et al. 2008; Yakubu 2016). In some abattoirs, poultry are also processed (Tekki et al. 2012). Furthermore, Onunkwo et al. (2003) reported cattle, sheep, goats and pigs being slaughtered at the Main abattoir in Nsukka, Tekki et al. (2012) reported that about 15 cattle, 20 goats and 8 sheep were slaughtered daily at the Jos slaughter facility. They reported that the slaughter facility has been serving the communities for over 30 years. Similarly, there has been the tendency to see different animal species being slaughtered on the same location within abattoirs and slaughter slabs as Ibrahim (2016) reported such situations at the Gusau Abattoir in Zamfara State. This could be because, for most abattoirs, no special areas are designated for slaughtering different animal species or the abattoir authorities do not enforce the use of specific locations for the slaughter and flaying of carcasses. For example, Onunkwo et al. (2003) reported cattle, sheep, goats and pigs being slaughtered at the Main abattoir in Nsukka. There are also reports of dogs, donkeys and horses being slaughtered for human consumption in some states of Nigeria. (Shehu et al., 2019).

\section{Slaughter methods}

In Nigeria the officially approved slaughter method is the Halal slaughter method though one could find stunning methods being operated here and there. For example, Joseph (1999) in his investigations on cattle slaughtering and post-mortem handling practices in selected Nigerian cities, reported the absence of stunning and proper meat processing operations. He further reported that animals were slaughtered in places that were frequently polluted with blood and faecal materials, and there were no fly and rodents protected facilities at the slaughter places. He also reported that meat produced thereof was 
prone to quick deterioration due to high level of bacterial contamination.

\section{Ante mortem and post mortem inspections}

With regard to meat inspection, Adebowale (2019) reported that it was mostly performed by Para veterinarians with routine protocol during such meat inspection being visual inspection, palpation and incision of visceral organs. He and other workers further reported operation being in mixed form with clean and dirty work being on simultaneously and that the flaying and processing of the carcasses were done on the floor (Adebowale, 2019; Nwanta et al., 2008).

Poor ante-mortem and post-mortem inspection at slaughter facilities can similarly aggravate the transfer and spread of animal diseases to humans as Lawan et al. (2010) reported that there was none or scanty ante-mortem and post-mortem meat inspection in most abattoirs under their study.

Similarly, Yakubu (2016) reported very few abattoir workers were using protective clothing. The absence of meat inspection records as reported by Lawan et al. (2010) could make tracing of infections/diseases difficult. Furthermore, the trend, whereby revenue generation is emphasized more than disease surveillance at slaughter facilities will negate any effort to trace diseases outbreaks, should they occur, especially that Lawan et al. (2010) reported that there were scanty records of operations at most of the abattoirs under their study.

\section{Abattoir wastes management}

There are many reports of poor management of abattoir wastes in almost all slaughter facilities in Nigeria (Nwanta et al. 2008; Cadmus et al., 2010; Lawan et al., 2010). For example, Adeyemo (2002) reported numerous waste and microbial organisms being produced during abattoir operation in many abattoirs. Others like Callaway et al. 2004; Esona et al. 2004; Abiade-Paul et al. 2006) further gave worse scenario, especially with regard to challenges to effective environmental management and associated decreased quality of life among animal and human population at the slaughter facilities.

This scenario might have resulted in the number of different types of infectious agents being reported from animals brought to these facilities (Kaltungo 2013; Yakubu 2016). For example, Adetosoye et al. (1976) reported isolating hemolytic Echerichia coli (E. coli) from diarrheic piglets that might have found their way to slaughter. Yakubu (2016) reported finding small ruminants slaughtered at the Kaduna Metropolis abattoir being positive for Brucella antibodies while reported demonstrating Brucella suis and Brucella abortus by using PCR in goats at the Zaria Small Ruminants Slaughter Slab.
Reports of isolating a number of bacteria from the solid wastes of slaughter facilities in Nigeria include those of Litchfield (1980), Elder et al. (2000) and Abiade-Paul et al. (2006). In her study, Kaltungo (2018b) was able to demonstrate Brucella melitensis antibodies in camels in Katsina State, Nigeria and many of these camels could have found their way to slaughter.

Adeyemi and Adeyemo (2007) classified the wastes at Nigerian abattoirs to include condemned organs, carcasses, blood, hides, horns, hooves, hair, paunch content and carcass trimmings. These wastes could contain microbes that could be infective to humans. Even for the aesthetic reasons, such wastes should be better disposed of (Adeyemi and Adeyemo, 2007). In their contribution to the knowledge on abattoir wastes management in Nigeria, studied the direct and indirect effects of management of abattoirs on the quality of local built environment and the health of residents in their vicinity using Ogbomoso as a case study. They collected water samples from selected wells in their study area and analyzed them. They also interviewed residents in buildings located approximately $100 \mathrm{~m}$ radius to the abattoir with a view to determine possible effects of the abattoir management of their health. The result was analyzed using frequency count, chi-square and correlation test. The study indicated results of the water samples and interviews from the study showed that the pollution of wells and air quality of the local built environment in the vicinity of the abattoir might have caused the coughing, typhoid fever, diarrhea, and malaria and muscle pains among the residents in neighbourhood to the abattoir.

Tekki et al. (2012), in a study at a market in Jos South Local Government Area of Plateau State, Nigeria reported that the abattoir wastes were not restricted to the abattoirs but also to the markets where butchers took their meat for sale. They reported that the smell and sight of the heaps of wastes were unpleasant as ingesta, blood, horns and polythene bags among other unidentifiable materials could be seen littering the locations.

\section{Diseases commonly encountered at slaughter}

Studies in Nigeria have revealed many infectious agents being demonstrated in animals being slaughtered in Nigeria with consequent potential risks to human health (Cadmus et al. 2010; Tekki et al. 2012; Kaltungo 2013; Yakubu 2016). These infectious agents include Echerichia coli (E. coli) O157, Salmonella and Campylobacter (Tekki et al. 2012). Others include Brucella abortus, Brucella melitensis, Brucella suis, and Salmonella spp (Cadmus et al. 2010; Kaltungo (2018a, b). Some infectious agents that can cause disease in humans have been demonstrated in slaughtered animals in Nigeria also include Mycobacterium tuberculosis, Mycobacterium bovis, 
Leptospira spp, Campylobacter sp, Yersinia sp, Clostridia spp, Listeria, among others (Adesemoye et al. 2006; Opara et al. 2006). Nwanta et al. 2008; Ahmad 2015; Danbirni 2016; Ibrahim 2016; Shehu et al. 2019). This might have led Nwanta et al. (2008) to suggest that the upsurge in the prevalence of communicable and zoonotic diseases such as tuberculosis, cysticercosis, trichinosis among others in Nigeria could be accounted by the existence of these diseases in animals at slaughter. Thus, the continuous accumulation of wastes in our abattoirs could continue to pose significant challenges in environmental health and management along with increasing decrease in air quality of the environment. Not only that the increasing antimicrobial resistance as reported by workers like Shehu et al. (2020) could continue to pose severe risks on human health in Nigeria.

\section{Presence and activities of abattoir personnel}

For any slaughter facility to operate optimally, there must be adequate personnel that will ensure best execution of sanitary measures along with handling wastes and disease reporting and control measures. However, the situation is always there judging by the reports of a number of researchers like Ahmad (2015), Yakubu (2016) among others.

In a study to determine the status of bovine tuberculosis in Gusau abattoir, Ahmad (2015) reported veterinarians, Animal Health Scientists, butchers, cattle handlers among workers engaged in the abattoir. Similarly, Nwanta et al. (2008). The Veterinary inspector by virtue of his position as the technical and sanitary director of the abattoir is responsible for the control of establishment at every stage of operations so that he can exercise maximum supervision and intervene as rapidly as possible when required. Legislation must be enacted to describe approval for all establishment intended for use or in use at abattoirs and in all premises where meat or meat products are stored, processed and/or sold.

\section{Butchers and their activities: knowledge, attitude and practices}

A number of researchers have looked into the activities of abattoir workers with regard to slaughter management. For example, Alhaji and Baiwa (2015), in a questionnaire study involved a total of 385 respondents and reported $57.2 \%$ of them to have Secondary level education while $22.8 \%$ had Primary School Leaving Certificate and $5.1 \%$ had Tertiary education $14.9 \%$ having no formal education.

With regard to the knowledge of abattoir workers on animal diseases, Nwanta et al. (2008) reported some of the workers to have hostile attitude as evidenced by their refusing to take up modern meat processing along with involving private practitioners and delineation of functions of the various professionals in the abattoir. This inclination could have been due to the fact that majority of the abattoir workers did not have any previous training in meat hygiene (Alhaji and Baiwa 2015). With regard to their knowledge on abattoir processing which includes management, hygiene and waste management, the same authors reported that $74.5 \%$ of the respondents had poor knowledge about effective and efficient slaughterhouse operations. Furthermore, they also observed that only $56.6 \%$ of the respondents had knowledge about the actual meaning of slaughterhouse and that they regarded cleaning of cutting utensils and surface (17.4\%) as preventive practice. Also, the same authors further reported that only $16.3 \%$ of the abattoir workers knew about the role of protective capacity of frequent cleaning and sanitation of slaughterhouse facilities. They similarly, reported that $33.4 \%$ of the respondents knew about incineration to be a means of wastes disposal, $30.5 \%$ of them considered burying wastes in the abattoir burial while $9.3 \%$ agreed that there could be by-products processing as a waste management process in the abattoir. The issue here is that many of the abattoir authorities might not be enforcing the appropriate steps to be taken in the management of abattoirs. Furthermore, the poor maintenance culture in Nigeria might have led to most of the facilities that are installed newly completed abattoirs to waste away and become redundant.

One would say here that there are some of the abattoir workers who may know the importance of adequate operations and environment health as $39.2 \%$ and $37.7 \%$ of the respondents respectively indicating that $21.6 \%$ of them knew these factors to have effects on animal health even though $86.2 \%$ of them reported engaging in poor practices (Alhaji and Baiwa 2015).

\section{Meat and meat products transportation}

Meat and meat products transportation from slaughterhouses to the market is a very important aspect of wholesome meat production. In Nigeria, the situation can be said to be left to be much desired. For example, Nwanta et al. (2008) reported carcasses being transported in boots of taxis, dirty pickup vans, motor cycles, carts and wheel barrows. They also reported street hawking of meat in open head pans to be increasing in many cities. Meat transportation at abattoirs is by the use of old trucks, motor cycles and wheel burrows (Lawan et al. 2010). Thus, there could be the chances of mixing carcasses as well as contamination of meat in the process. 


\section{Conclusion}

The managing of abattoirs and slaughterhouses should be left entirely to Local governments and private entrepreneurs nationwide. This is in line with the Federal government of Nigeria current position about the operations of public utilities, also of the success of such ventures when private entrepreneurs are involved. Meat Inspection and hygiene Act shall be enacted and signed into law to allow for proper implementation and enforcement of the law by the governments and staff. This will ensure proper management of the abattoirs and efficient meat inspection and hygiene. Provision of waste disposal system such as incinerators are recommended. The drainage system should be upgraded and modernized. Awareness on the use of abattoir waste (manure) for biogas production and subsequent use of slurry thereafter as fertilizer is also recommended. Community education program should be mounted to educate the slaughter slabs workers on the zoonotic diseases in the study area.

\section{Acknowledgements}

The authors were grateful the University Management for providing access to the internet services used and also the Departmental Secretary of the Department of Veterinary Medicine for typing the manuscript.

\section{Authors' contributions}

$\mathrm{SI}, \mathrm{BYK}$, and $\mathrm{HBU}$ analyzed and extracted relevant information from the various sources of the literature obtained. AYB, FUM, and HMD did the search for the various papers used in this research. SNA was the major contributor in writing the manuscript. All authors read and approved the final manuscript.

\section{Funding}

Not applicable in this section.

\section{Availability of data and material}

The authors declared that the review work data are available online. In addition, all data generated during this study are included in this manuscript.

\section{Declarations}

Ethics approval and consent to participate

Not applicable in this section.

\section{Consent for publication}

Not applicable in this section.

\section{Competing interest}

The authors declare that they have no known competing financial interests or personal relationships that could have appeared to influence the work reported in this paper.

\section{Author details}

${ }^{1}$ Department of Veterinary Medicine, Ahmadu Bello University, Zaria, Nigeria. ${ }^{2}$ Veterinary Teaching Hospital, Ahmadu Bello University, Zaria, Nigeria. ${ }^{3}$ Samaru College of Agriculture, Ahmadu Bello University, Zaria, Nigeria. ${ }^{4}$ Department of Veterinary Medicine, University of Ilorin, Ilorin, Nigeria. ${ }^{5}$ Department of Veterinary Services, Ministry of Agriculture and Natural Resources, Abuja, Katsina State, Nigeria.

Received: 7 May 2021 Accepted: 9 July 2021

Published online: 28 July 2021

\section{References}

Abiade-Paul CU, Kene IC, Chah KF (2006) Occurrence and antibiogram of Salmonellae in effluent from Nsukka Munincipal abattoir. Niger Vet J 1:48-53

Adebowale $\mathrm{OO}$ (2019) Waste management and practices in a slaughterhouse in Abeokuta Nigeria: case study, implications and alternative. Sokoto J Vet Sci 17(3):52-55

Adetosoye AT, Willinge HT, Award M (1976) Enterotoxigenicity of hemolytic $E$. coli isolated from diarrheic piglets. Niger Vet J 5:3334

Adeyemi IG, Adeyemo OK (2007) Waste management practices at the Bodija Abattoir, Nigeria. Int J Environ Stud 64:71-82. https://doi.org/10.1080/ 00207230601124989

Adeyemo OK (2002) Unhygienic operations of a city abattoir in South Western Nigeria: environmental implication. AJEAM/RAGEE 4(1):23-27

Ahmad I (2015) Survey of tuberculosis in slaughtered cattle in Gusau abattoir, Zamfara State, Nigeria. MSc Dissertation, Ahmadu Bello University, pp $1-016$

Alhaji NB, Baiwa M (2015) Factors affecting workers' delivery of good hygienic and sanitary operations in slaughterhouses in north-central Nigeria. Sokoto J Vet Sci 13(1):29-37

Blood DC, Studdert VP (1990) Bailliere's comprehensive veterinary Dictionary Oval Road, London NW1 7DX, pp 24-28

Cadmus SIB, Adesokan HK, Adedokun BO, Stack JA (2010) Seroprevalence of bovine brucellosis in trade cattle slaughtered in Ibadan, Nigeria, from 2004-2006. J S Afr Vet Med Assoc 81:50-53

Cadmus SIB, Atsanda NN, Oni SO, Akang EEU (2004) Bovine tuberculosis in one cattle herd in Ibadan in Nigeria". Vet Med 49(11):406-412

Callaway TR, Anderson Edrington TS, Genovese KJ (2004) What are we doing about Escherischia coli 0157: H7 in cattle? J Anim Sci 82:E93-E99

Danbirni S (2016) Epidemiology of tuberculosis in cattle and human patients in Adamawa and Taraba States, Nigeria. PhD thesis, Ahmadu Bello University, Zaria, Nigeria, pp 1-170

Dasuki Commission (1976) The Reports on Local Government Reforms and Administrations in Nigeria

Elder RO, Keen JE, Siragusa GR, Barkocy-Gallaghen GA, Koohmaraie M, Lagreid WW (2000) Correlation of entero haemorrhagic E. coli 0157 prevalence in faeces, hides and carcasses of beef cattle during processing. Proc Natl Acad USA 97:2999-3003

Esona MD, Umoh JU, Kwaga JKP (2004) The prevalence and antibiogram of Salmonella spp and Escherischia coli from meat, milk, bovine rectal swabs and human stool in Zaria, Nigeria. J Anim Prod Res 19(1,2):7-19

Fasanmi FE (2002) Management of Abattoir: Nigerian experience. In: Proceedings of a national workshop on abattoir management and public health organized by Nigerian Veterinary Medical Association at women Development centre Abuja. 10-17

Fitzgerald AJ (2010) A social history of the slaughterhouse: from inception to contemporary implications. Res Hum Ecol 17(1):58-69

Food and Agriculture Organization of the United Nations Rome (2019) Africa Sustainable Livestock 2050, pp 12-14

Ibrahim S (2016) Epidemiology of tuberculosis in cattle and human patients in Bauchi and Gombe States, Nigeria. PhD thesis, Ahmadu Bello University, Zaria, Nigeria, pp 1-149

Joseph JK (1999) Investigations of cattle slaughtering and post-mortem handling in selected Nigerian cities. Niger J Anim Prod 26:106-110

Kaltungo BY (2013) Survey of brucellosis in Sheep and Goats in Kaduna North Senatorial District of Kaduna State, Nigeria. M.Sc. Thesis, Ahmadu Bello University Zaria, pp 1-155

Kaltungo BY (2018b) Sero-prevalence and risk factors for Brucella melitensis in camels in two Local Government Areas of Katsina State, Nigeria. Project submitted to College of Veterinary Surgeons Nigeria for the award of Fellow, College of Veterinary surgeons Nigeria, pp 1-56

Kaltuyngo BY (2018a) Serological and participatory studies of Brucella infections in small ruminants in Katsina and Sokoto States, Nigeria. Ph.D. Thesis, Ahmadu Bello University Zaria, pp 1-143

Guidelines for the Humane Slaughter of Animals: 2020 Edition, AVMA

Lawan MK, Bello M, Raji MA (2010) The public health implications of the operational activities of butchers in abattoirs. Paper presented at the Nigerian Veterinary Medical Association annual congress held vat the auditorium, College of Health Sciences, Benue State University, Benue State, Nigeria 4th-8th October, 2010

Litchfield JH (1980) Salmonella food poisoning. In: Safety of food (2nd edition). AVI Publishing Company, Inc., Connecticut, pp120-122 
Merck Veterinary Manual (MVM) (1998) Eighth Edition: Merck \& Co. Inc. White house station, N. J., USA

Muhammad MH (2017) Determination of epidemiological factors associated with bovine tuberculosis in selected Local Government Areas of Katsina State, Nigeria. Master in Tropical Veterinary Medicine, Ahmadu Bello University, Zaria, Nigeria, pp 1-128

Nwanta JA, Onunkwo Jl, Ezenduka VE, Phil-Eze PO, Egege SC (2008) Abattoir operations and waste management in Nigeria: a review of challenges and prospects. Sokoto J Vet Sci 7(2)

Odeyemi O (1991) Consequence of water pollution by solid phase and faecal materials in Nigeria. In: Akinyale L, Omueti J, Imevbore T (eds) Proceedings of the 3rd national conference on water pollution, June, 1991 Port Harcourt, Nigeria

Onunkwo TF, Wzeokonkwo RC, Obiegbulem SI (2003) Observations made during meat inspection atbthe main abattoir, Nsukkja, Nigeria. Niger Vet J 24(3):52-56

Opara MN, Ukpong UM, Okoli IC, Anosike JC (2006) cystisercosis of slaughter cattle in south eastern Nigeria. Ann N Y Acad Sci 1081:339-346
Shehu HA, Mukhtar AG, Adetoyinbo II, Ojo AO, Mus'ab UA (2020) Phytochemical screening and antibacterial activities of cassia fistula leaf extracts on some selected pathogens. J Pharmacogn Phytochem 9(3):1779-1783

Shehu AZ, Sani BN, Nuhu A, Hassan KM, Ahmad TT (2019) Abattoir as a tool for veterinary extension and communication services: a practical demonstration of its implementation. Open J Vet Med 9:1-10

Tekki IS, Nwankpa ND, Dashe Y, Owolodun OA, Elisha LA (2012) Mangement: a case report of a Local Abattoir in Jos South, Plateau State, Nigeria. Vom J Vet Sci 9:40-46

Yakubu YB (2016) Seroprevalences of Brucella in small ruminants, knowledge, attitude and practices of small ruminant owners in Kaduna metropolis, Kaduna State, Nigeria. MSc thesis, Ahmadu Bello University, Zaria, Nigeria, pp 1-119

\section{Publisher's Note}

Springer Nature remains neutral with regard to jurisdictional claims in published maps and institutional affiliations.

\section{Submit your manuscript to a SpringerOpen ${ }^{\circ}$ journal and benefit from:}

- Convenient online submission

- Rigorous peer review

- Open access: articles freely available online

- High visibility within the field

- Retaining the copyright to your article

Submit your next manuscript at $\boldsymbol{\nabla}$ springeropen.com 